Journal of Applied Fluid Mechanics, Vol. 10, Special Issue, pp. 69-77, 2017.

Selected papers from International Conference on Newer Engineering

Concepts and Technology, ICONNECT2K17, 2017

Available online at www.jafmonline.net, ISSN 1735-3572, EISSN 1735-3645.

DOI: $10.36884 / \mathrm{jafm} .10$. SI.28272

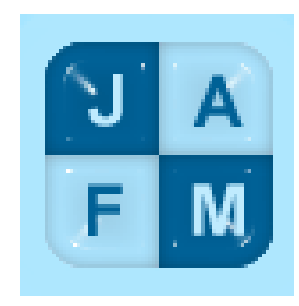

\title{
Wind Tunnel Investigation of Downstream Wake Characteristics on Circular Cylinder with Various Taper Ratios
}

\author{
G. Balaji ${ }^{\dagger \dagger}$ S. Nadaraja Pillai ${ }^{2}$ and C. Senthil $\operatorname{Kumar}^{1}$ \\ ${ }^{1}$ Department of Aerospace Engineering, Madras Institute of Technology, Anna University, Tamil Nadu, India \\ ${ }^{2}$ School of Mechanical Engineering, SASTRA University, Tamil Nadu, India
}

†Corresponding Author Email: gbalajiaero@gmail.com

(Received February16, 2017; accepted July 30, 2017)

\begin{abstract}
Circular cylindrical towers which are sporadically seen in engineering structures such as buildings, towers, etc are basically considered as bluff body. The flow around the circular cylindrical structures gained interest among the researchers. Since there has been lot of development in infrastructure, transport, telecommunication in the last two decades. Such cylindrical towers invite more attention, since the failure of circular cylindrical tower/ structures is not only due to the surface pressure distribution but also due to the effect of wake induced by the flow separations. Even though there are engineering challenges in circular cylindrical structures, different designs of structures such as stepped cylinders, rough cylinder and taper cylinder etc. are used in various applications. The flow field downstream is relatively less explored for the tapered circular cylinder than other cylinders. Effects of downstream wake due to such cylindrical structures are not only affecting other structures downstream but also induce vibration on itself. In this paper, circular cylinders of various taper ratios are considered for the study at various sub critical Reynolds number. Extensive wind tunnel studies were performed on various taper ratios ranging from 0.6 to 1 in the increment of 0.1 for various $\mathrm{x} / \mathrm{D}$ and $\mathrm{h} / \mathrm{D}$ locations using hot wire anemometer. Various parameters like wake width, dissipation length, wind speed ratios were measured downstream for various taper ratios. The result shows that the magnitude of wake width gradually increases with increase in downstream distance along with increase in taper ratio whereas dissipation length and wind speed ratio increases with decrease in taper ratio.
\end{abstract}

Keywords: Wind speed ratio; Dissipation length; Wake width; Velocity deficit; Tower wake.

\section{INTRODUCTION}

In recent years, an array of cylindrical structures is prevalently seen in engineering. Some of the typical examples include offshore structures, marine risers, a group of chimney stacks, stays, masts, closely separated skyscrapers etc. In the design of cylindrical structures, fluctuating fluid forces, dominant shedding frequencies, structural vibrations, acoustic noise and geometrical parameters like taper ratio, location are some of the primary considerations. The structural failure of the cylindrical structures is most likely due to the aforementioned phenomena and such engineering structural disasters claims hundreds of lives and billions of dollars. Failures in practical applications are reported in (Chen et al. 2003; Chen 1987a, 1987b; Paidoussis 1980a, 1981b, 1983c, 1992d; Blevins et al. 1990) with a view to enhance the aesthetics of the buildings and to ascertain the customers' requirements the variation of the taper ratio becomes unavoidable. However, those variations in the taper ratio on the design of the buildings complicate the downstream flow which in turn leads to the failure of the nearby structures as well as the induced vortices affects itself by means of vibration. Orlando et al. (2011) experimentally investigated the complexities of the downstream flow over meteorology tower and claimed that the disturbed downstream flow may cause shadowing effect on anemometer which under predicts the wind speed. Further, they added that the wind speed deficit downstream of the tower can be up to a maximum of $35 \%$ for lower wind speeds and $18 \%$ for higher wind speed. It is well known that the wake downstream eventually mixes with the 


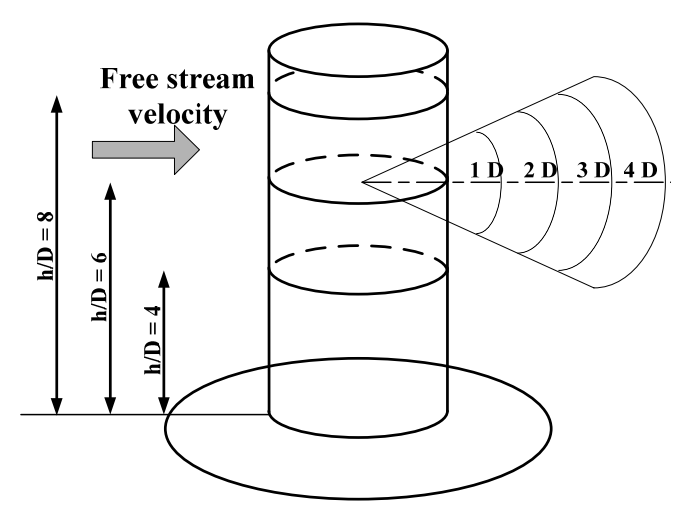

(a)

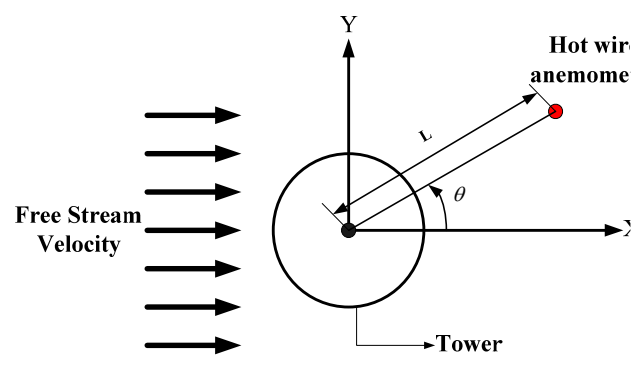

(b)

Fig. 1. Schematic of the experimental setup (a) front view, (b) top view.

atmospheric wind result in the increase in wake width which depends upon incoming turbulence. $\mathrm{Li}$ et al. (2016) confirmed the above fact by both the experimental and numerical analysis. They observed that the recovery of wind velocity and the expansion of wake width were promoted by the turbulence of the inflow Subramanian et al. (2016) confirmed that the oncoming turbulence induced by the terrain influences the downstream wake. Seo et al. (2013) experimentally investigated the drag reduction over the smooth cylinder and grooved cylinders. When the grooved cylinder was used the wake width decreased by $18.4 \%$ relative to the smooth cylinder and the wake recovery at $12.3 \%$. However, the authors have not considered the taperness of the cylinder.

Lam and Peng (2016) investigated the wake characteristics of a vertical axis wind turbine by $2 \mathrm{D}$ and 3D CFD simulations. It is observed that maximum velocity deficit at 3D downstream which has been predicted at both $2 \mathrm{D}$ and $3 \mathrm{D}$ CFD simulations and maximum velocity deficit to $85 \%$ at blade mid span predicted in three dimensional models. Singha et al. (2009) performed water tunnel tests to show the vertical variation of the velocity field in the near region of a shallow wake. Their results showed that the recirculation zone was seen small near the bed and tends to grow in to a larger recirculation zone in the mid-depths. Moreover, to study the effect of turbulent wakes generated by twin parallel cylinder Nosier et al. (2012) carried out experimental investigations. They reported that the spacing ratio $\mathrm{s} / \mathrm{d}$ between the cylinders plays a vital role in determining the wake growth and its interactions. Agelin-Chaab and Tachie (2013) found that aspect ratio and angle of incidence lead to the head loss in flow past rectangular cylinder in open channel. Also it is observed that self-similarity was obtained by proper choice of velocity and length scale and irrespective of angle of incidence $(\theta)$ and aspect ratio (L/D). Liu et al. (2014) numerically investigated the porous material coating on of bluff body. It is observed that flow characteristic of near wake of circular cylinder modified by the porous coating in different aspect of frequency and amplitude. Further it is found that fluctuating wake velocity and aerodynamics force has been removed by the porous coating on the circular cylinder.

Naturally, there is pressing need to study and to understand the fluid dynamics associated with cylindrical tower structures in cross flow. Cylindrical tower structures are considered to be the simple configuration shown in Fig.1 (a and b). Fluid dynamics interference in the circular cylindrical towers may give rise to flow separation, flow switching, reattachment, vortex impingement, recirculation, quasi-periodic vortices and vortex street interaction, involving most of the generic flow features associated with tower structures. Thus, flow around cylindrical tower structures provides an excellent model for gaining insight into the underlying flow physics around uniform and tapered cylindrical structures. The study of the various taper ratio cylindrical tower structure wakes has gained a momentum in past decades, as is evident from the distribution of relevant publication collected largely from journal.

In the present research, the downstream velocity at various locations with different $\mathrm{d} / \mathrm{D}$ and $\mathrm{h} / \mathrm{D}$ ratios is analaysed. The goal of this research is to quantify the downstream flow velocity using the terms wind speed ratio $(\beta)$, dissipation length $(\delta)$ and wake width $(\varphi)$. The definition of the terms are given below.

Wind speed ratio

$(\beta(\theta))=\frac{\mathrm{U}_{\text {downstream }}}{\mathrm{U}_{\text {upstream }}}$

where $U_{\text {downstream }}$ is the velocity in the downstream and $U_{\text {upstream }}$ is the free stream velocity. Dissipation length $(\delta)$ is the along wind maximum downstream distance at which complete decay of wake occurs or attaining the free stream velocity. Wake width $(\varphi)$ is the across wind maximum distance at which the velocity of the flow attains freestream velocity.

Taper Ratio $[\lambda]$ : It is defined as ratio between diameter at tip of the circular tower to diameter at base of the tower.

Taper ratio 
$[\lambda]=\frac{D_{\text {Tip of the circular tower }}}{D_{\text {Base of the circular tower }}}$

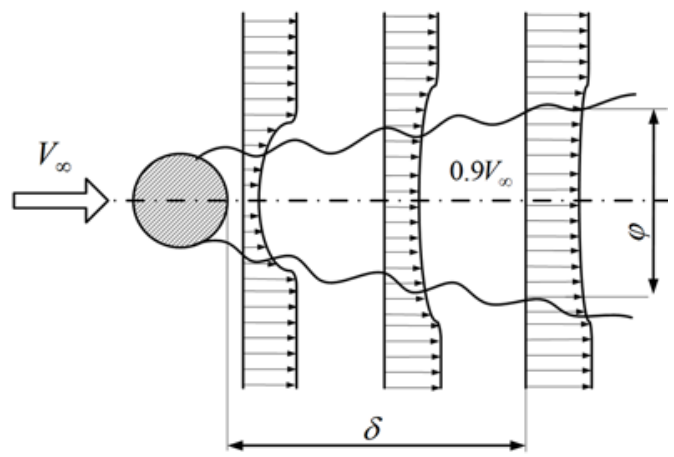

Fig. 2. Wake width definition in the downstream of the circular Cylinder.

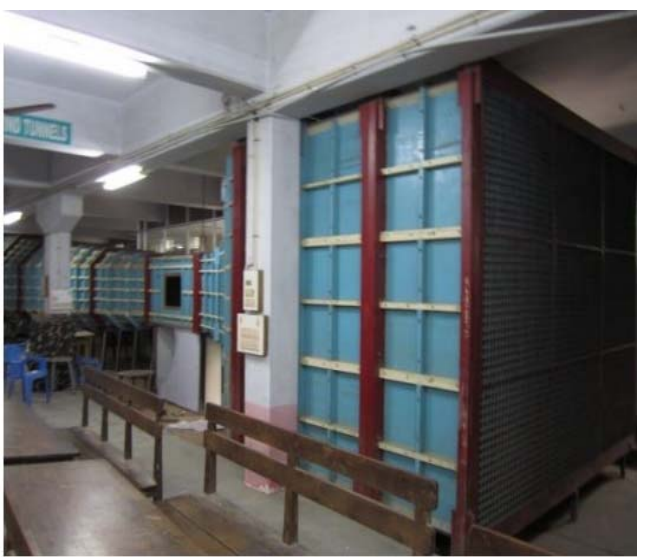

Fig. 3. Low speed subsonic wind tunnel.

\section{EXPERIMENTAL PROCEDURE}

To quantify the wake width and dissipation length in wind tunnel experiments, the degree of distortion of flow in the various downstream distances at different $\mathrm{x} / \mathrm{D}$ and $\mathrm{h} / \mathrm{D}$ ratios were measured considering different taper ratio as shown in Fig.2. In this section, the complete experimental apparatus used for the wind tunnel measurements were described. The experimental apparatus mainly consisted of a low speed subsonic wind tunnel, a hot wire anemometer, numerically controlled traverse mechanism and data acquisition system. The experiments were performed in a low-speed subsonic wind tunnel with the dimension of the test sections as $1.8 \mathrm{~m}$ long, $1.2 \mathrm{~m}$ wide and $0.9 \mathrm{~m}$ deep as shown in Fig 3 . This facility with its current configuration can produce nominal wind speeds up to $45 \mathrm{~m} / \mathrm{s}$ with turbulence intensities in the range of less than 5\%. A separate three-axis computer numerically controlled traverse mechanism set-up mounted with hot wire anemometer probe has been utilized in this experimental study. Fig.4 is a schematic diagram illustrating the traverse mechanism setup.

The minimum linear translation step size of up to $0.1 \mathrm{~mm}$ can be achieved with high precision and spatial resolution. The angular movement of the probe covers $-45^{0}$ to $45^{0}$ with the step of $5^{0}$ around the circular cylindrical tower model. Similarly, the spatial distance of up to $240 \mathrm{~mm}$ behind the model can be measured over the height of $260 \mathrm{~mm}$ from the tower top to the base A kimo single-sensor miniature boundary layer hot-wire probe (type CTV 110) has been employed for the velocity measurements which can measure the velocities ranging between 0 to 30 $\mathrm{m} / \mathrm{s}$ with a sampling frequency of $200 \mathrm{~Hz}$. The hot wire anemometer system used in the present study utilizes numerically controlled traverse mechanism set-up system, National Instruments Data acquisition system (type NI-6000) and a PC used for data storage and control.

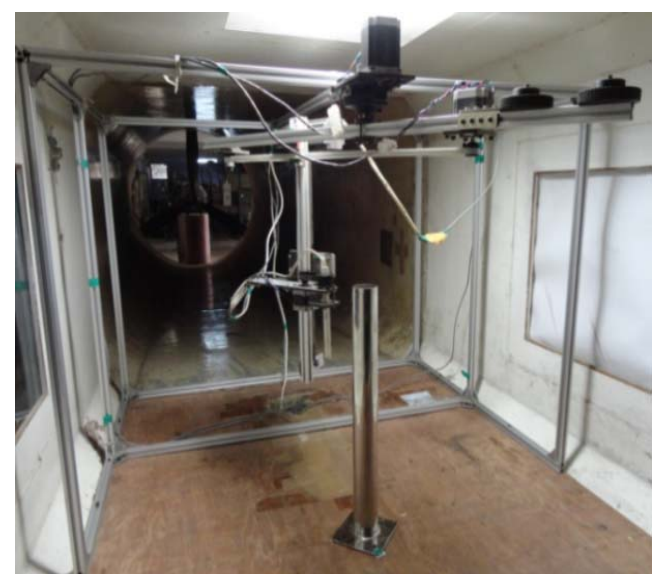

Fig. 4.Tower model with traverse mechanism.

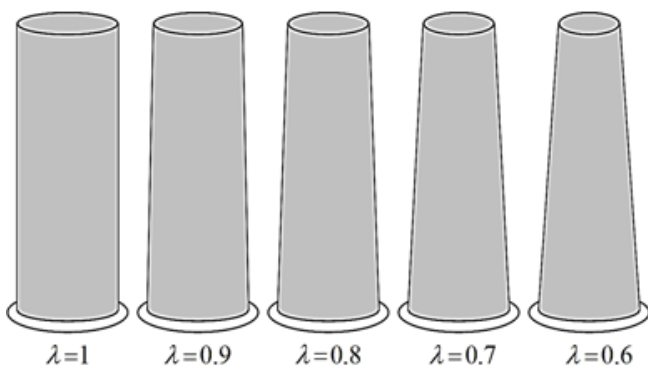

Fig. 5. Uniform and tapered Circular Cylinder.

The test model circular cylindrical towers with varying taper ratios were fabricated using stainless steel material. The circular cylindrical tower model has uniform length of $450 \mathrm{~mm}$ and base diameter of $50 \mathrm{~mm}$. However, while varying the taper ratio for the cylindrical tower it goes down to $30 \mathrm{~mm}$ in the case of taper ratio 0.6. Fig.5 illustrates the cylindrical tower model with various taper ratio and its geometrical specifications. In the wind tunnel, the cylindrical tower models were mounted in the centre of the test section with their axes perpendicular to the freestream flow. The blockage ratio for the models in the tunnel was calculated as $2.02 \%$ and is unlikely to cause a significant blockage effect in this study (Saathoff and Melbourne 1987). The experiments were conducted at 5,10 and $15 \mathrm{~m} / \mathrm{s}$. It is clear that studies

the 


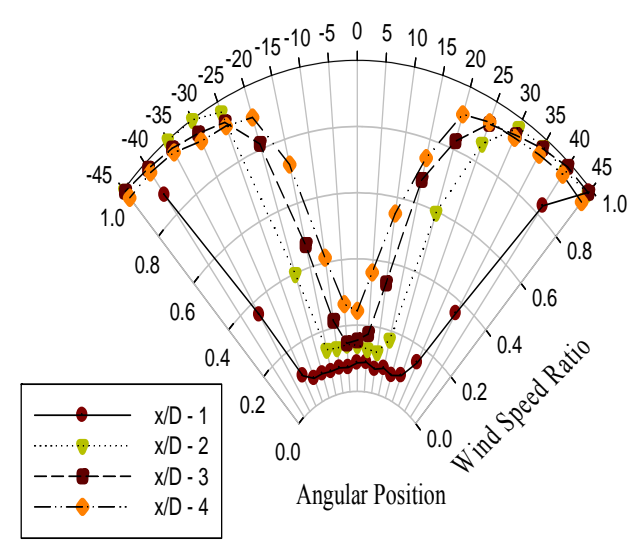

(a) $\lambda=1$

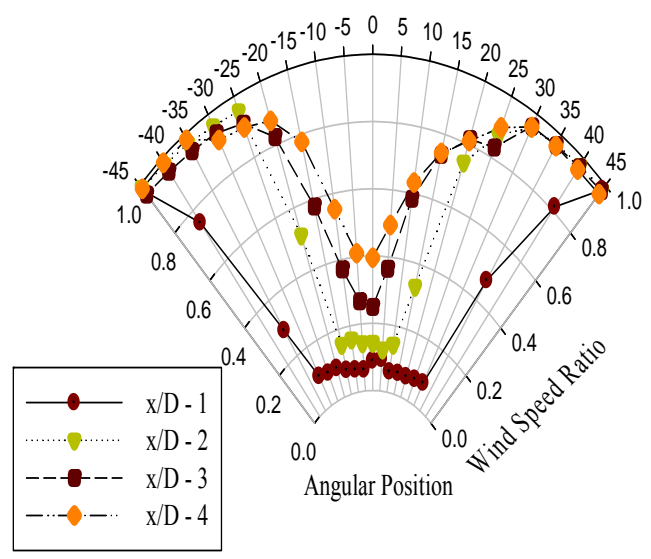

(c) $\lambda=0.8$

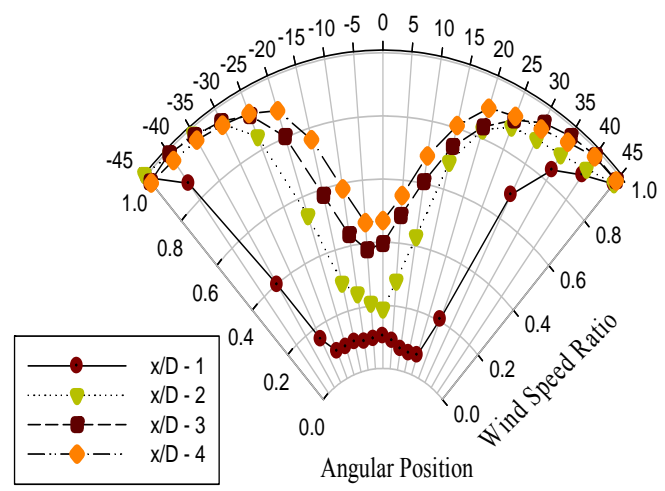

(e) $\lambda=0.6$

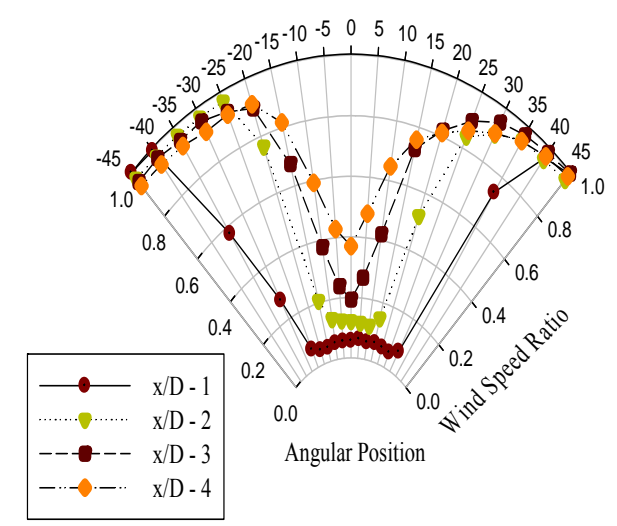

(b) $\lambda=0.9$

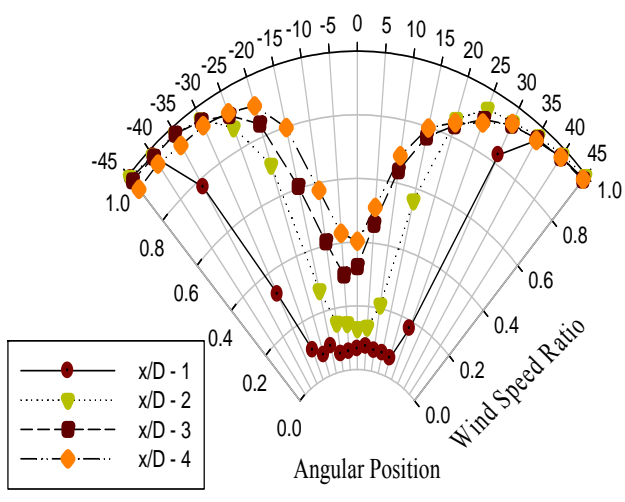

(d) $\lambda=0.7$

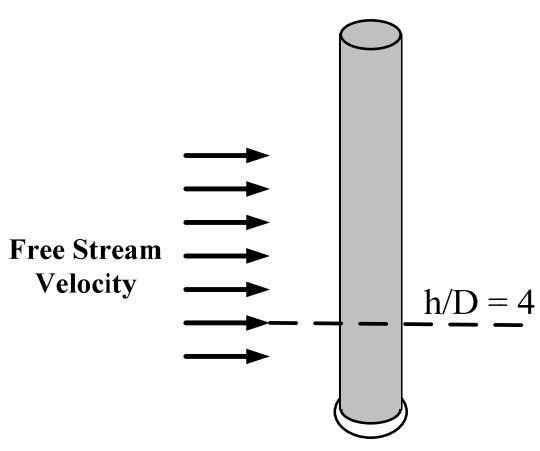

(f) Freestream velocity at $\mathrm{h} / \mathrm{D}=4$

Fig. 6. Effect of wind speed ratio $[\beta]$ on circular cylinder at $h / D=4$.

wake of tower at various taper ratios were least reported in the literatures which forms the motivation for the present study. The current work has been focused on quantifying the decreased wind velocity at different downstream locations and to characterize the downstream wake in terms of wake width of the tower at various taper ratios.

\section{RESULTS AND DISCUSSION}

Prior to conducting the wind tunnel experiments on the circular cylinder the data were measured in the $\mathrm{X}-\mathrm{Y}-\theta$ planes of the test section in order to characterize the flow. In this section, the results of the experimental analysis performed on the low speed subsonic wind tunnel, operating at velocities 


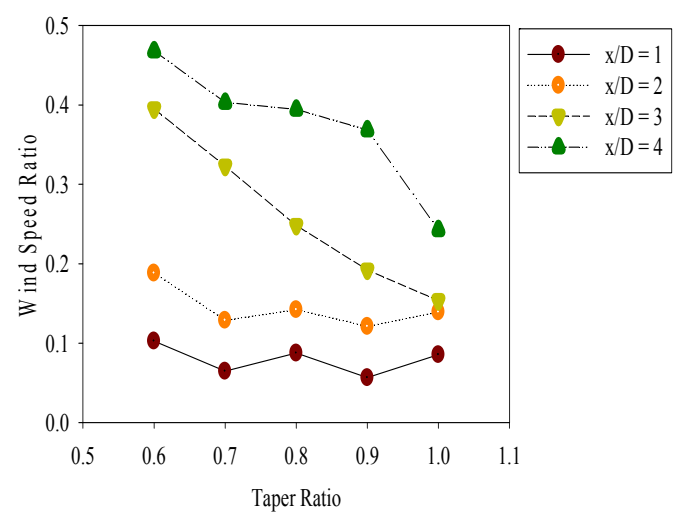

(a). Dissipation length at $\mathrm{h} / \mathrm{D}=4$

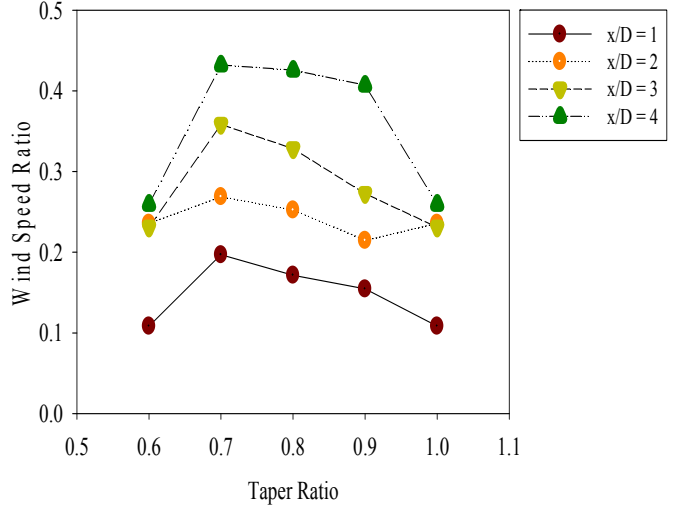

(b). Dissipation length at $\mathrm{h} / \mathrm{D}=6$

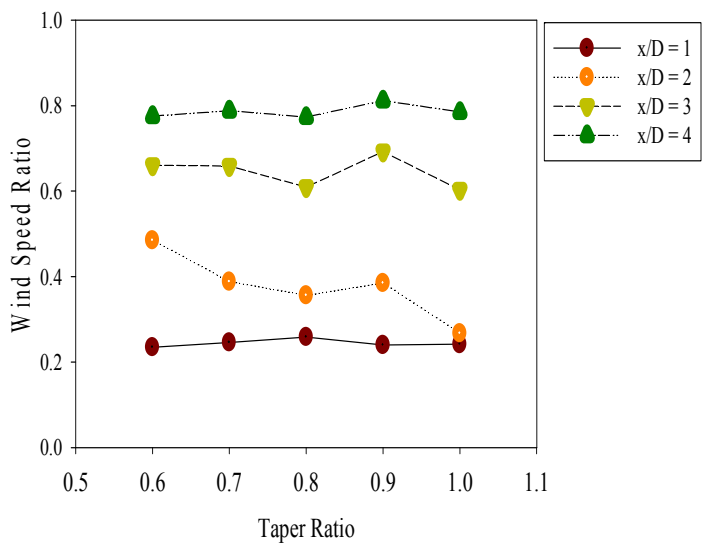

(c). Dissipation length at $\mathrm{h} / \mathrm{D}=8$

Fig. 7. Dissipation length on various $h / D$ ratios.

ranging between $5-15 \mathrm{~m} / \mathrm{s}$ with uniform and tapered cylindrical models were compared with the measured wake wind speed ratios, wake width, dissipation length at various $\mathrm{x} / \mathrm{D}$ and $\mathrm{h} / \mathrm{D}$.

\subsection{Effect of Wind Speed Ratio $[\beta]$ on Circular Cylinder}

The wind speed profiles in the downstream location were measured for various $\mathrm{x} / \mathrm{D}$ i.e. $\mathrm{x}$, varies with respect to the downstream distance and $\mathrm{D}$, refers to the diameter of the circular cylinder. However, the downstream distance were limited to $\mathrm{x} / \mathrm{D}=4$ since, the test section has limited length. Along the $\mathrm{x}$-axis, downstream the wind speed ratio measured shows the formation of wake region which leads to the velocity deficit. In the $\theta$ direction downstream at a particular instant the velocity deficit becomes unity where the wake velocity and the freestream velocity become equal. An increase in the downstream distance the increase in wind speed ratio is evident from the Fig.6 (a-e). i.e. behind the center line of the downstream cylindrical tower wind speed ratio varies from $0.26,0.39,0.4,0.4$ and 0.48 respectively. The decrease in taper ratio, the wind speed downstream increases. It can be seen from the Fig.6 (a-e) that the wind speed ratio recovery has been happening with decrease in taper ratio. From Fig.6 (a) that the wind speed ratio on the axial direction along the axis of the circular cylinder is 0.26 and it starts increasing with decrease in taper ratio from Fig.6 (b-e) i.e. wind speed ratio varies from 0.39 to 0.48 . This wind speed ratio recovery is most likely due to the diffusivity of the freestream air with the wake region at decrease in taperness of the circular cylinder. Thus, consistently increasing wind speed ratio with respect to decrease in taper ratio is justified. However, attaining wind speed ratio $[\beta]=$ 1 is not possible with such a distance up to $4 \mathrm{D}$.

The velocity measurement has been performed at various $h / D$ ratios downstream of the circular cylinder with various taper ratios. The effect of the taper ratio on the wind speed ratio at various $\mathrm{h} / \mathrm{D}$ is represented in the Fig.7. It can be clearly seen from the Fig.7 (a) wind speed ratio lies in 0.1 , that there is a constant wind speed ratio at $\mathrm{x} / \mathrm{D}=1$ and to a some extent $\mathrm{x} / \mathrm{D}=2$ for various taper ratios. This is most likely due to the immediate downstream wake from the circular cylinders. However, increasing $\mathrm{x} / \mathrm{D}$ i.e. at $x / D=3$ and 4 decreasing trend can be seen with the increase in taper ratio. In this moment, it is necessary to understand that the increase in the taper ratio means that decrease in taperness. For example if the taper ratio $[\lambda]$ is equal to 1 it means that there is no taperness. But, the taper ratio of 0.6 denotes the high degree of taperness for the models 


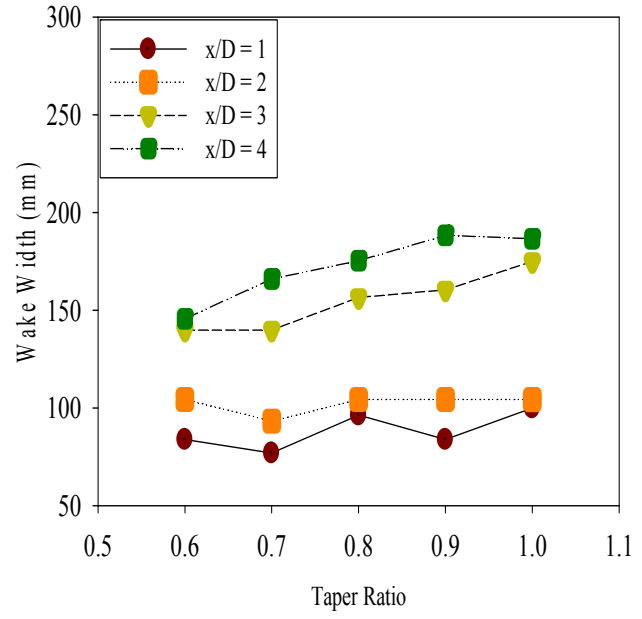

(a) $h / D=4$

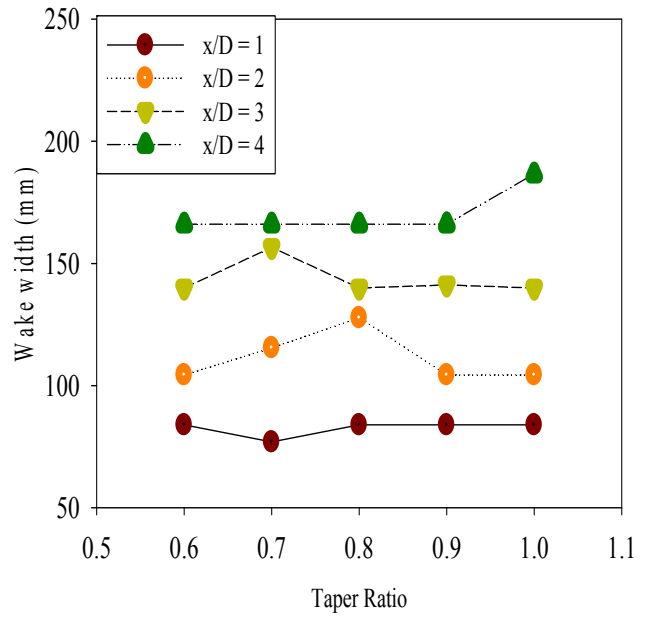

(b) $h / D=6$

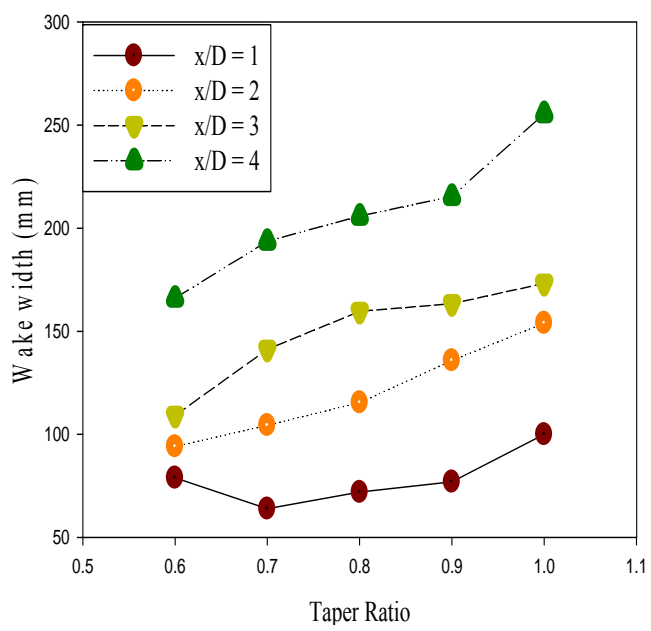

(c) $h / D=8$

Fig. 8. Effect of Wake width at various taper ratio $[\lambda]$.

considered in this present study. With the increases in $\mathrm{h} / \mathrm{D}$ ratio the wake region tries to stabilize at all $\mathrm{x} / \mathrm{D}$ which is evident from the Fig.7 (a-c) i.e. wind speed ratio attained 0.8 at $\mathrm{x} / \mathrm{D}=4, \mathrm{~h} / \mathrm{D}=8$. This is because the increase in $\mathrm{h} / \mathrm{D}$ necessarily means that the increase in the height of the circular cylinder at the height $\mathrm{h} / \mathrm{D}=8$ which is almost near the free end. At the free end, the freestream velocity influences the downstream wake.

\subsection{Effect of Dissipation Length $[\delta]$}

Ideally the dissipation length is the one at which the wake velocity should be equal to the freestream velocity. However, there are limitations in measuring this dissipation length since it requires a longest test section as per the Helmholtz theorem. Helmholtz theorem says that (i) vortex cannot end in a fluid (ii) It needs a solid boundary, hence this research has limited measuring the dissipation length based on wind speed ratio till $\mathrm{x} / \mathrm{D}=4$. It is found that this dissipation length, increases with decrease in $h / D$ ratio. As $\mathrm{h} / \mathrm{D}$ ratio increases the $\mathrm{x} / \mathrm{D}$ ratio decreases inorder to attain the dissipation length. Also, the increase in taper ratio leads to decrease in the dissipation length. Attaining the highest wind speed ratio at $\mathrm{x} / \mathrm{D}$ can be considered as a dissipation length. For example, in Fig. 7 (c) that at $\mathrm{x} / \mathrm{D}$ ratio $=4$ the wind speed ratio is 0.8 .

\subsection{Effect of Wake Width $[\varphi]$ on Various Taper Ratios $[\lambda]$}

Figure8 (a, b, c) shows the wake width varies with the taper ratio for various $\mathrm{x} / \mathrm{D}$ and $\mathrm{h} / \mathrm{D}$. It is found that increase in downstream location there is an increase in wake width i.e. varies from $83.905 \mathrm{~mm}$ to $255.51 \mathrm{~mm}$. However, close to the circular cylinder irrespective of the taper ratio the wake width becomes almost constant at every $\mathrm{h} / \mathrm{D}$. This is because of closure to the circular cylinder in the downstream the strength of the circulation is dominating and not dissipated with the freestream velocity. At $h / D=8$, the tip effect dominates and the wake width becomes proportional to the tip diameter of the cylinder that in turn corresponds to the taper ratio. 


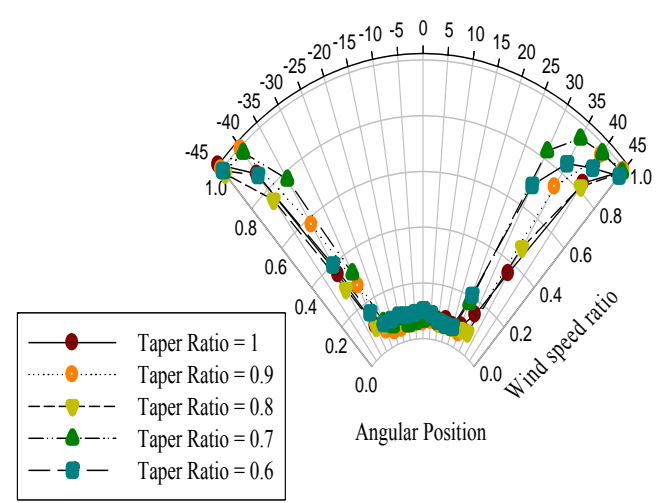

(a) $x / D=1$

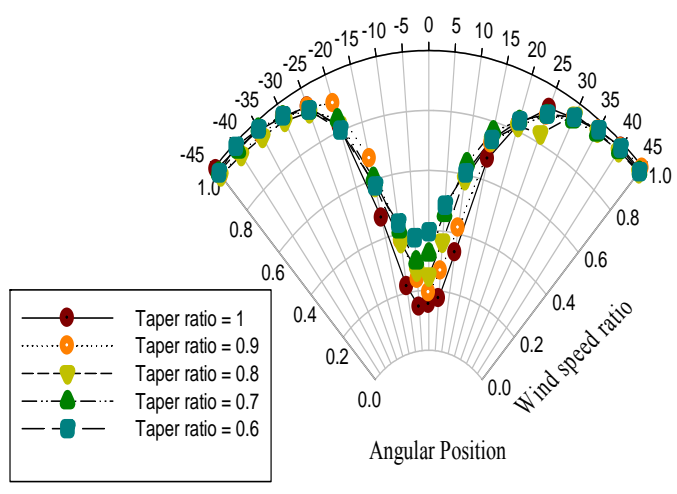

(c) $x / D=3$

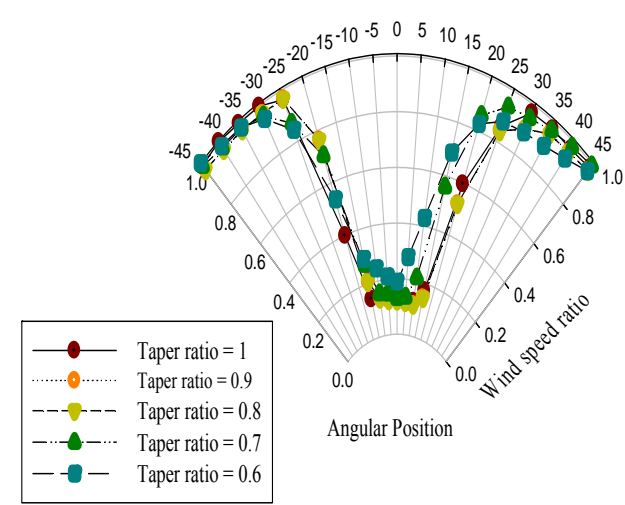

(b) $x / D=2$

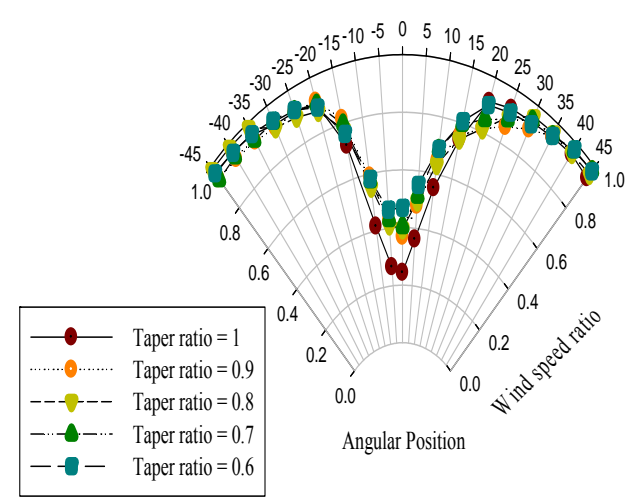

(d) $x / D=4$

Fig. 9. Effect taper ratio of the circular cylinder at $h / D=4$.

\subsection{Effect of Taper Ratio $[\lambda]$}

The Wind speed ratio measurements were taken at various $\mathrm{x} / \mathrm{D}$ downstream distances and $\mathrm{h} / \mathrm{D}$ at their corresponding downstream distances. For example Fig.9 (a) shows that the wind speed ratio distribution for 1D downstream distance and h/D ratio of 4 .

The wind speed distribution shows that the taper ratio of the circular cylinder influences in such a way that the decrease in trend is inferred. The decreasing trend with the increase in taper ratio is due to the dissipation of the downstream flow with the freestream velocity. It is quite agreeable that the increasing taper ratio in the geometry leads to decrease in diameter in the maximum height of the tower which in turn produces lower wake. However, increase in downstream the wake width also disappears as shown in Fig.9 (b-d) as well as in Fig.10 (a-d).

In Fig.11 (a-d) it can be clearly seen that the flow freestream mixes and dominates with the downstream wake region and tries to attain normalized velocity. The normalized velocity is the resultant of freestream velocity and the wake velocity. At a point where the taper ratio is higher as $(\lambda=0.6)$ the wind speed ratio downstream shows 85 $95 \%$ as depicted in Fig.11 (d).

\section{CONCLUSIONS}

Wind speed measurement in the downstream of the circular cylinder structures with various taper ratio has been investigated and the factors like Wind speed ratio $(\beta)$, wake width $(\varphi)$ and dissipation length were calculated. The following conclusions were made based on the investigation.

The wind speed ratio $(\beta)$ increases with increase in the downstream distance of the cylindrical structures. Wind speed ratio $(\beta)$ is insignificant with respect to the height of the tower except near the tower top. It is inferred that the magnitude of wake width gradually increasing with increasing downstream distance of the circular cylindrical. Also, it is observed that the wake width $(\varphi)$ increases with increase in taperness of the cylinder. The dissipation length, increases with decrease in taper ratio of the cylinder and also increase with increase in downstream distance in all the $\mathrm{h} / \mathrm{D}$ ratios. It is observed that dissipation decay occurs quickly at top of the tower, i.e., $h / D=8$ than $h / D=4$ and 6 , because of the tower top free stream wind. The downstream wind speed profile clearly states that wind speed deficit decrease with increase in taperness in all $x / D$ and $\mathrm{h} / \mathrm{D}$ locations. The investigations were performed in such a way that the measurements are limited to the downstream length till 4D. 

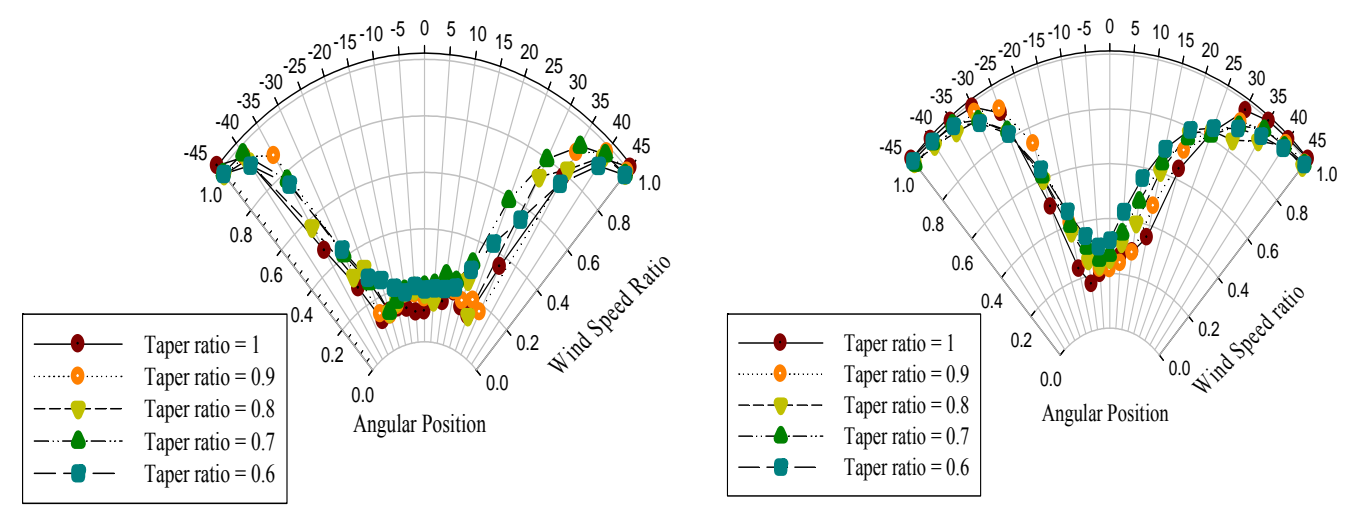

(a) $x / D=1$

(b) $\mathrm{x} / \mathrm{D}=2$

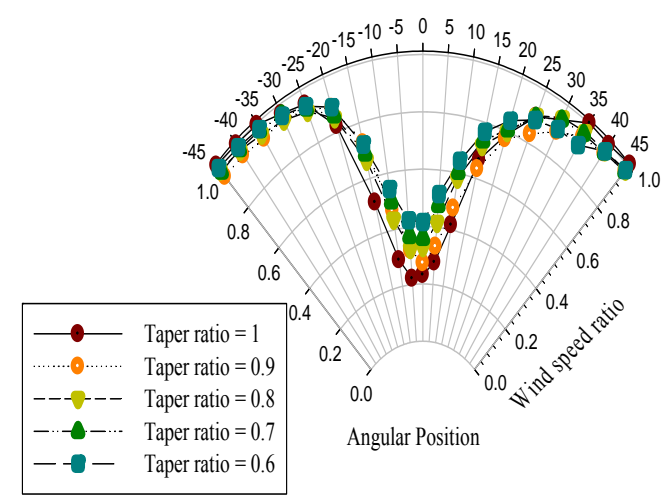

(c) $\mathrm{x} / \mathrm{D}=3$

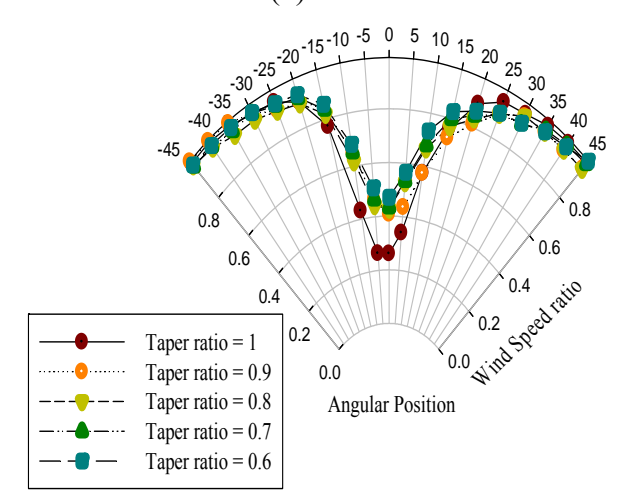

(d) $x / D=4$

Fig. 10. Effect taper ratio of the circular cylinder at $h / D=6$.

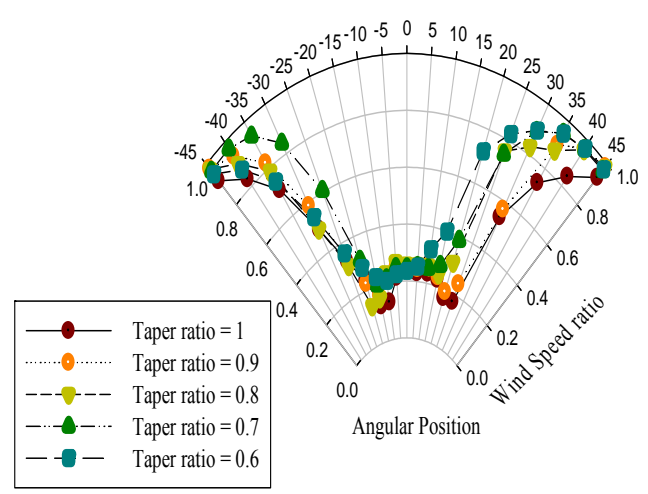

(a) $x / D=1$

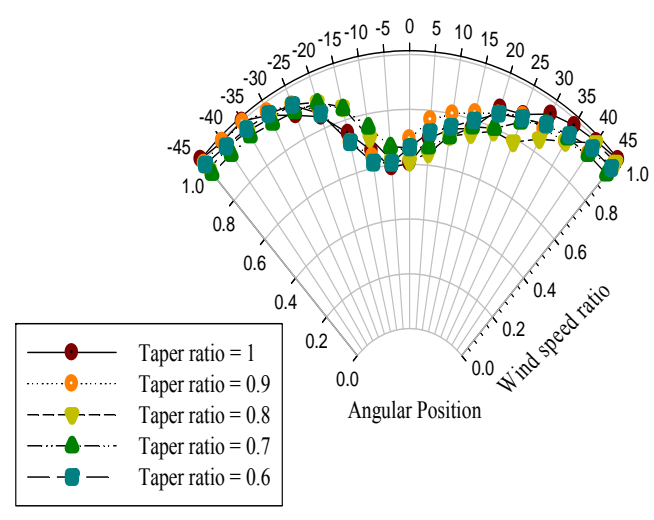

(c) $x / D=3$

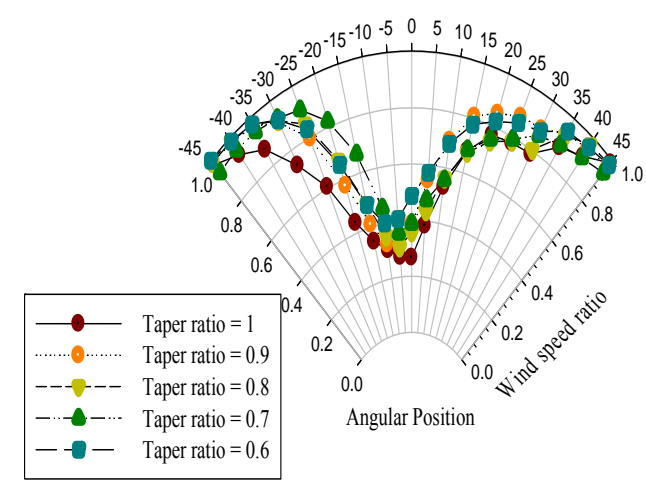

(b) $x / D=2$

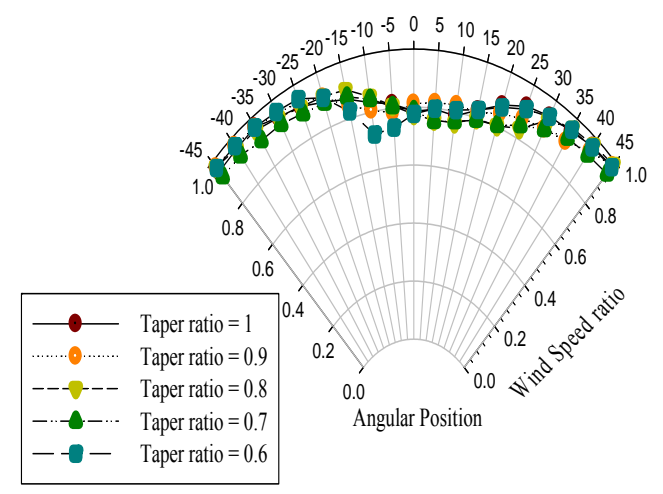

(d) $x / D=4$ 
Fig. 11. Effect taper ratio of the circular cylinder at $h / D=8$.

\section{REFERENCES}

Agelin Chaab, M. and M. F. Tachie (2013). Open Channel Turbulent Flow past Rectangular Cylinders at Incidence. Journal of Hydraulic Engineering 139(12), 1309-1313.

Blevins, R. D. (1990). Flow-induced vibration.

Chen, L., J. Y. Tu and G. H. Yeoh (2003). Numerical simulation of turbulent wake flows behind two side-by-side cylinders. Journal of fluids and structures 18(3), 387-403.

Chen, S. S. (1987a). Flow-induced vibration of circular cylindrical structures.

Chen, S. S. (1987b). A general theory for dynamic instability of tube arrays in cross flow. Journal of Fluids and Structures 1(1), 35-53.

Lam, H. F. and H. Y. Peng (2016). Study of wake characteristics of a vertical axis wind turbine by two-and three-dimensional computational fluid dynamics simulations. Renewable Energy 90, 386-398.

Li, Q. A., J. Murata, M. Endo, T. Maeda and Y. Kamada (2016). Experimental and numerical investigation of the effect of turbulent inflow on a Horizontal Axis Wind Turbine (part II: Wake characteristics). Energy 113, 1304-1315.

Liu, H., J. Wei and Z. Qu (2014). The interaction of porous material coating with the near wake of bluff body. Journal of Fluids Engineering 136(2), 021302.

Nosier, M. A., A. R. Elbaz, T. A. Fetouh and L. A. El Gabry (2012). Characteristics of turbulent wakes generated by twin parallel cylinders. Journal of Fluids Engineering 134(12), 121201.

Orlando, S., A. Bale and D. A. Johnson (2011). Experimental study of the effect of tower shadow on anemometer readings. Journal of
Wind Engineering and Industrial Aerodynamics 99(1), 1-6.

Paidoussis, M. (1992d). Some Curiosity-Driven Research in Fluid Structure Interactions and Current Applications, PVP-1O 1992 Calvin Rice Lecture. In ASME Winter Annual Meeting 1992.

Paidoussis, M. P. (1980a). Flow-induced vibrations in nuclear reactors and heat exchangers. Practical Experiences and State of Knowledge in Practical Experiences with FlowInduced Vibrations 1-81.

Paidoussis, M. P. (1981b). Fluidelastic vibration of cylinder arrays in axial and cross flow: state of the art. Journal of Sound and Vibration 76(3), 329-360.

Paidoussis, M. P. (1983c). A review of flow-induced vibrations in reactors and reactor components. Nuclear Engineering and Design 74(1), 31-60.

Saathoff, P. J. and W. H. Melbourne (1987). Freestream turbulence and wind tunnel blockage effects on streamwise surface pressures. Journal of Wind Engineering and Industrial Aerodynamics 26(3), 353-370.

Seo, S. H., C. D. Nam, J. Y. Han and C. H. Hong (2013). Drag reduction of a bluff body by Grooves laid out by design of experiment. Journal of fluids engineering 135(11), 111202.

Singha, A., A. M. Shinneeb and R. Balachandar (2009). PIV-POD investigation of the wake of a sharp-edged flat bluff body immersed in a shallow channel flow. Journal of Fluids Engineering 131(2), 021202.

Subramanian, B., N. Chokani and R. S. Abhari (2016). Aerodynamics of wind turbine wakes in flat and complex terrains. Renewable Energy 85, 454-463. 